University for Business and Technology in Kosovo

UBT Knowledge Center

UBT International Conference

2012 UBT International Conference

Nov 2nd, 9:00 AM - Nov 3rd, 5:00 PM

\title{
Material Balance Adjustement in Raw Material Processing
}

Migena Hoxha

University of Tirana, migenahoxha@gmail.com

Piro Zoga

Polytechnic University of Tirana, pzoga@yahoo.com

Aida Bode

Polytechnic University of Tirana, boaal@yahoo.com

Follow this and additional works at: https://knowledgecenter.ubt-uni.net/conference

Part of the Computer Sciences Commons, and the Engineering Commons

\section{Recommended Citation}

Hoxha, Migena; Zoga, Piro; and Bode, Aida, "Material Balance Adjustement in Raw Material Processing" (2012). UBT International Conference. 66.

https://knowledgecenter.ubt-uni.net/conference/2012/all-events/66

This Event is brought to you for free and open access by the Publication and Journals at UBT Knowledge Center. It has been accepted for inclusion in UBT International Conference by an authorized administrator of UBT Knowledge Center. For more information, please contact knowledge.center@ubt-uni.net. 


\title{
Material Balance Adjustement in Raw Material Processing
}

Migena HOXHA *, Piro ZOGA **, Aida BODE **

\author{
*University of Tirana, Faculty of Natural Science, Industrial Chemistry Department, Albania \\ e-mail:migenahoxha@gmail.com \\ ** PolytechnicUniversity of Tirana, Mineral Resources Engineering Department, Albania \\ e-mail:pzoga@yahoo.com, boaal@yahoo.com
}

\begin{abstract}
Circuit of one processing plant was studied in order to adjust the mass balance. The granulometric composition of the streams that belong to grinding and classifying processes was analysed, while the chemical content was determined only at the streams related to separation process. Three connection matrixes are considered in this paper, one corresponding to the size fraction equations, the second corresponding to the chemical content measurements and the third, the solid flow rate balance. The technique used consisted of filtering all the data by a weighted least-squares procedure. Then running the output data in a custom designed feature of the computer program MATLAB. The raw data was then corrected and the different missing assays calculated and presented here.
\end{abstract}

Key words: mass balance, adjustment, Matlab, flowsheet

\section{Introduction}

Mass balance calculation is requested in all industrial processes where material transformation is done (chemical plants, mineral processing, metallurgy, food industry etc.). It makes it possible to determine the streams flow rates, chemical compositions, particle size distributions and other parameters.

The material balance reflects in every case the mass conservation law which states that material is never lost but mearly changes state. Experimental measurements in industrial or pilot flow-sheets must be available to calculate these balances. Carrying out such material balances is often found to be a difficult task. This is due to several reasons: firstly, the errors of the measurements (related to the accu racy of sensors, sampling methods, chemical analyses etc.); second, in most cases, main variables such as the stream flowrates are not measured; also, several properties may be simultaneously considered and the flowsheet can become overly complicated creating problems of solving complex mass balance equations.

Improved calculation capability developments using computers, makes it possible to solve complex problems through measured data adjustment.

Material balance methods have been developed which use all the available plant data, adjusting them in order to produce a best fit material balance [Bloise, 1991]. Some mass balance packages are also available.

In general, the method assumes that all measured data contains errors and these errors are minimised by the procedure which generates adjusted values against a predetermined criterion. The experimental assays are then processed in order to make them satisfy the mass conservation equations. The calculations results are the best estimation of the true assay values.

The objective of this paper is to demonstrate the balancing data calculation technique for a complex circuit case with missing measurements. The application was studied in a mineral processing plant, but the technique may be generic and thus applicable in other industrial circuits.

\section{The Analysed Circuit}

The analysed processing plant consists of grinding circuit where size reduction is combined with granulometric classification. One separation process for the partial metal recovery is also pres ent in this circuit. 


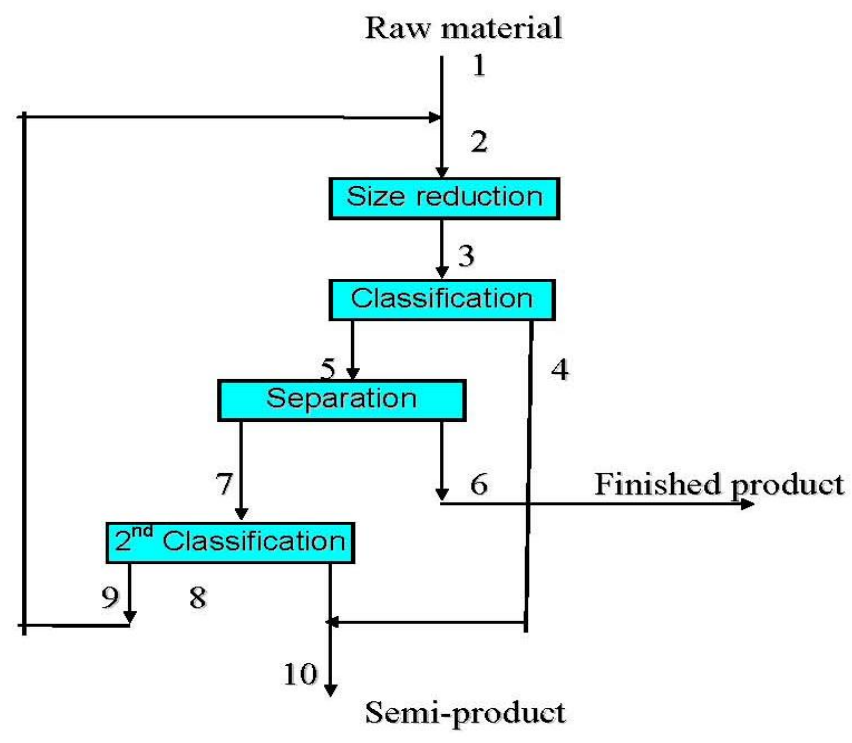

Fig. 1. Process flowsheet

The schematic drawing of the circuit is presented in fig.1. Samples were collected manually in the specified points indicated in Fig.1 and listed in Table 1. according to a time length previously established. There are ten streams and seven samples have been taken in order to analyse the granulometric composition. Only 3 streams in the entry and the exits of separation process have been sampled and analysed for chemical content determination. The measured variables are presented in the following tables below:

\begin{tabular}{|l|c|c|c|c|}
\hline Stream & 5 & 6 & 7 \\
\hline Metal content \% & 18.11 & 48.01 & 17.04 \\
\hline
\end{tabular}

\begin{tabular}{|c|c|c|c|c|c|c|c|}
\hline Size fraction & Stream 1 & Stream 4 & Stream 5 & Stream 7 & Stream 8 & Stream 9 & Stream 10 \\
\hline+1.6 & 78.0 & 0.3 & 14.0 & 6.7 & 1.1 & 15.1 & 1.0 \\
\hline$-1.6+1.25$ & 1.4 & 1.8 & 11.1 & 6.6 & 1.3 & 11.1 & 1.5 \\
\hline$-1.25+0.8$ & 1.8 & 7.7 & 18.7 & 14.9 & 3.5 & 26.3 & 4.6 \\
\hline$-0.8+0.315$ & 4.2 & 30.4 & 29.1 & 23.6 & 17.7 & 30.2 & 21.8 \\
\hline$-0.315+0.074$ & 8.2 & 38.7 & 22.1 & 32.1 & 46.1 & 16.1 & 43.9 \\
\hline-0.074 & 6.4 & 21.1 & 5.0 & 16.1 & 30.3 & 1.2 & 27.2 \\
\hline Total & 100.0 & 100.0 & 100.0 & 100.0 & 100.0 & 100.0 & 100.0 \\
\hline
\end{tabular}

Table 1. Measured values

\section{Mass Balance Calculation}

The flowsheet is presented in terms of a graphical network schematic illustrated in Fig.2. The network can be mathematically represented by a connection matrix. Each row in the matrix corresponds with a given node and each column with a given stream. The element value is 1 if the stream enters the node; -1 if the stream exits from the node and 0 otherwise. 


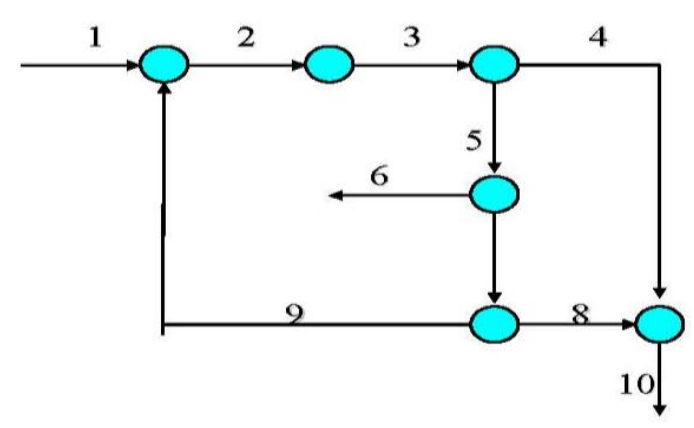

Fig. 2. The network corresponding to the grinding circuit

The mass conservation equations of the various components can be written in a condensed matrix form as follows :

solid phase conservation :

metal conservation :

size fraction "i"conservation :

$$
\begin{aligned}
& \mathrm{M} \mathrm{Q}^{*}=0 \\
& \mathrm{M} \mathrm{Q}^{*} \bullet \mathrm{C}^{*}=0 \\
& \mathrm{M} \mathrm{Q*} \bullet \mathrm{G}^{*} \mathrm{i}_{\mathrm{i}}=0
\end{aligned}
$$

with $\quad Q^{*}$ - real solids flowrate vector (dimension s )

$$
\begin{aligned}
& C^{*} \text { - real grade vector of metal (dimention } s \text { ) } \\
& G_{1} \text { - real size fraction " } i \text { "vector } \\
& \text { - } \quad \text { - Hadamard multiplication }
\end{aligned}
$$

The above written mass conservation equations cannot be verified for the measured values of the process variables as they usually contain random errors. The other types of errors in this procedure are not considered but it is possible to detect them by additional calculation. For this work, these errors were considered negligible. The technique used consisted of filtering the data by a weighted least-squares procedure applied to the model of mass conservation equations. The vector of filtered variables are those which minimise the function : $\wedge$

$$
\mathrm{F}=1 / 2\|\mathrm{HX}-\mathrm{X}\|^{2}
$$

under the constraints :

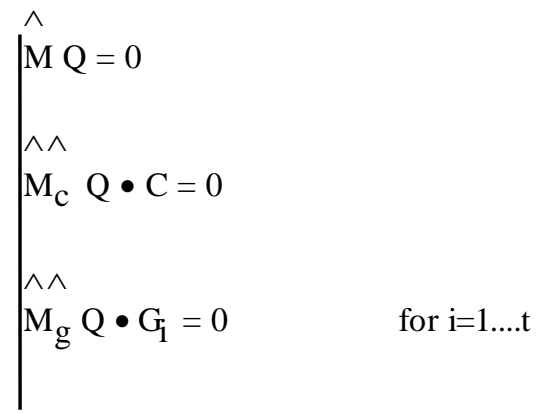

with $\mathrm{X}$ : the vector of measured parameters

$$
X=\left|\begin{array}{c}
Q \\
C \\
G_{1} \\
: \\
G_{t}
\end{array}\right|
$$

Q : vector of measured solids flowrate 
$C$ : vector of measured metal contents

$\mathrm{G}$ : vector of measured size fractions " $\mathrm{i}$ " $(\mathrm{i}=1 . . \mathrm{t})$

$\mathrm{V}$ : diagonal variance matrix of measurements

$\mathrm{H}$ : selective matrix of measurements

and $\mathrm{X}$ : vector of filtered variables

$\wedge$

\begin{tabular}{l|l}
$\wedge$ & \\
$\wedge$ & $\mathrm{C}$ \\
$\wedge$ & $\wedge$ \\
$\mathrm{G}_{1}$ \\
$\vdots$ \\
$\mathrm{G}_{\mathrm{t}}$
\end{tabular}

$\wedge$

$\mathrm{Q}$ : vector of measured solids flowrate

$\wedge$

C : vector of measured metal contents

$\wedge$

$\mathrm{G}$ : vector of measured size fractions " $i$ " $(\mathrm{i}=1 \ldots \mathrm{t})$

$\wedge$

$\mathrm{V}$ : diagonal variance matrix of measurements

$\wedge$

$\mathrm{H}$ : selective matrix of measurements

Q : vector of measured solids flowrate

$\mathrm{C}$ : vector of measured metal contents

$\wedge$

$\mathrm{G}$ : vector of measured size fractions " $\mathrm{i}$ " $(\mathrm{i}=1 . . . \mathrm{t})$

$\wedge$

$\mathrm{V}$ : diagonal variance matrix of measurements

$\wedge$

$\mathrm{H}$ : selective matrix of measurements

The method selected to solve the mass balance problem was based on linearizing the constraints. The calculation was carried out by running a new software macro based on MATLAB. The results of the material balance adjustement are presented in Table 2 .

In comparison with the raw data, a major advantage of the balanced data calculated by this method, is its respect to the mass conservation law.

On the other hand, the values of missing measurements was calculated which provides a greater insight into process characteristics.

The solid flow rates given in Table.2 are expressed in relative values and refer to the feed ore entering the grinding circuit. 


\begin{tabular}{|c|c|c|c|c|c|c|c|c|c|c|}
\hline \multirow{2}{*}{$\begin{array}{c}\text { ze fraction } \\
\text { mm }\end{array}$} & \multicolumn{10}{|c|}{ Stream } \\
\hline & 1 & 2 & 3 & 4 & 5 & 6 & 7 & 8 & 9 & 10 \\
\hline+1.6 & 78.0 & 53.4 & 11.8 & 0.4 & 14.0 & - & 7.3 & 1.1 & 14.2 & 0.9 \\
\hline$-1.6+1.25$ & 1.4 & 5.2 & 9.6 & 1.8 & 11.1 & - & 6.1 & 1.3 & 11.5 & 1.4 \\
\hline$-1.25+0.8$ & 1.8 & 11.4 & 16.9 & 7.7 & 18.7 & - & 14.5 & 3.5 & 26.6 & 4.6 \\
\hline$-0.8+0.315$ & 4.2 & 14.2 & 29.3 & 30.5 & 29.1 & - & 23.7 & 18.0 & 30.1 & 21.4 \\
\hline$-0.315+0.074$ & 8.2 & 11.3 & 24.7 & 38.7 & 22.1 & - & 31.9 & 46.1 & 16.2 & 44.1 \\
\hline-0.074 & 6.4 & 4.4 & 7.6 & 21.1 & 5.0 & - & 16.4 & 30.0 & 1.2 & 27.6 \\
\hline Total & 100.0 & 100.0 & 100.0 & 100.0 & 100.0 & & 100.0 & 100.0 & 100.0 & 100.0 \\
\hline Solid flowrate, $\%$ & 100.0 & 162.56 & 162.56 & 25.94 & 136.63 & 4.72 & 131.91 & 69.34 & 62.56 & 95.28 \\
\hline Grade, $\% \mathrm{Cr} 2 \mathrm{O} 3$ & - & - & - & - & 18.11 & 48.01 & 17.04 & - & - & - \\
\hline
\end{tabular}

Table 2. Material balancing results

\section{Conclusions}

The filtered data obtained by this procedure of material balance calculation can be used for generic calculations in any raw material processing. This approach is more reliable and allows a superior analysis and a better discrimination between different operations than most current methods.

It is a powerful tool in the evaluation of processing circuits and also allows the simulation of new processing flowsheets.

The presented procedure is considered generic as it is independent of the ore type, flowsheet dimensions and of the variables measured

\section{References}

Bloise R., Reinhard C.,Batina J. - Etablissement de bilans-matiere statistiquement coherents surdes unites complexes, Rev.Ind. Minerale, pp.257-263, mars 1981.

Ragot J., Aubrun M. - Equilibrage de bilans-matieres dans l'industrie minerale, Rev.Ind. Minerale, pp.93, 1979.

Mular A.L.,etc.- Mass Balance of a grinding circuit, CIM Bull., pp.124-129, december 1979.

Informatique dans l'industrie minerale, Mines et

Carrieres, 130-145, novembre 1988.

Zoga P. - Equilibrage de bilan matiere, memoire

CESEV, Nancy 1989. 